\title{
How do maternal interaction style and joint attention relate to language development in infants with Down syndrome and typically developing infants?
}

Article

Accepted Version

Creative Commons: Attribution-Noncommercial-No Derivative Works 4.0

Seager, E., Mason-Apps, E., Stojanovik, V., Norbury, C., Bozicevic, L. B. and Murray, L. (2018) How do maternal interaction style and joint attention relate to language development in infants with Down syndrome and typically developing infants? Research in Developmental Disabilities, 83. pp. 194-205. ISSN 0891-4222 doi:

https://doi.org/10.1016/j.ridd.2018.08.011 Available at https://centaur.reading.ac.uk/79361/

It is advisable to refer to the publisher's version if you intend to cite from the work. See Guidance on citing.

Published version at: http://dx.doi.org/10.1016/j.ridd.2018.08.011

To link to this article DOI: http://dx.doi.org/10.1016/j.ridd.2018.08.011

Publisher: Elsevier

All outputs in CentAUR are protected by Intellectual Property Rights law, including copyright law. Copyright and IPR is retained by the creators or other copyright holders. Terms and conditions for use of this material are defined in the End User Agreement. 


\section{www.reading.ac.uk/centaur}

\section{CentAUR}

Central Archive at the University of Reading

Reading's research outputs online 
How do maternal interaction style and joint attention relate to language development in infants with Down syndrome and typically developing infants?

Emily Seager; Emily Mason-Apps; Vesna Stojanovik; Courtenay Norbury; Laura Bozicevic; Lynne Murray 


\section{Highlights}

- Responding to joint attention is positively related to concurrent language in infants with Down syndrome (DS) aged 17-23 months

-Maternal interactive style is positively related to concurrent language in typically developing (TD) infants of equivalent non-verbal mental age

- Different social communication factors concurrently predict language in TD infants and infants with DS

What this paper adds?

This paper uniquely combines two different social factors (joint attention and maternal interactive style) in the same study and with the same group of infants with Down syndrome. This is the first study to have investigated a link between maternal interactive style and language development for children with Down syndrome. The study found that different social communication skills were associated with concurrent language skills in DS and in TD infants: in DS there was a moderate positive relationship between responding to joint attention and concurrent language skills, whereas in TD infants there was a moderate positive relationship between maternal interactive style and concurrent language skills.

Key words: interaction, Down syndrome, language, typically developing infants, joint attention 


\section{Abstract}

Down syndrome (DS) is more detrimental to language acquisition compared to other forms of learning disability. It has been shown that early social communication skills are important for language acquisition in the typical population; however few studies have examined the relationship between early social communication and language in DS. The aim of the current study is to compare the relationship between joint attention and concurrent language skills, and maternal interactive style and concurrent language skills in infants with DS and in typically developing (TD) infants matched for mental age. We also investigated if these relationships differ between children with DS and TD children. Twenty-five infants with DS (17-23 months) and 30 TD infants (9-11 months) were assessed on measures of joint attention, maternal interactive style and language. The results indicated a significant positive relationship between responding to joint attention (RJA) and concurrent language for the DS group, and a significant positive relationship between maternal positive expressed emotion (PEEM) and concurrent language for the TD group. We hypothesise that different social communication factors are associated with language skills in DS, at least between 17 and 23 months of age compared to TD infants of similar non-verbal and general language abilities. 


\subsection{Introduction}

Down syndrome (DS) is a genetic disorder caused by an additional copy of chromosome 21. It occurs in approximately 1 in 700 births (Martin, Klusek, Estigarribia \& Roberts 2009). The majority of individuals with DS have some form of learning disability, and the average IQ is 50 (range 30 to 70) (Chapman \& Hesketh, 2000). The neuro-cognitive profile of individuals with DS is characterised as having strengths and weaknesses. Although children and adults with DS are reported to be highly sociable and have good 'people' skills (Fidler, Most, Booth-LaForce \& Kelly, 2008), language is a significant area of weakness. Expressive language skills tend to be more impaired than receptive language abilities (Fidler \& Nadel, 2007) and can sometimes be poorer than expected from their general non-verbal functioning (Chapman \& Hesketh, 2000). A recent meta-analysis showed that children with DS had significant deficits in expressive vocabulary, compared to typically developing (TD) children match ed for nonverbal mental age (NVMA; Næss, Lyster, Hulme \& Melby-Lervåg, 2011), while receptive vocabulary skills were in line with NVMA. Receptive vocabulary and gesture production are considered relative strengths (Galeote, Sebastian, Checa, Rey \& Soto, 2011). Severe early delays have been reported in language developmental milestones. For example, children with DS produce their first word, on average, at 21 months in comparison to 12 months for TD children (Stoel-Gammon, 2001). Following initial delays, expressive vocabulary continues to develop slowly in DS. Using the Swedish Early Communicative Inventory, the performance of children with DS aged 36 months was reported to be comparable to that of TD children aged 16 months (Berglund et al., 2001).

Given the pivotal role that language plays in development, it is of paramount importance that we attempt to understand the contributing factors, especially in children with DS, as their language abilities can be particularly impaired, although there is wide within 
syndrome variability. One factor that is likely to be of importance is early social communication skills, and, in spite of the generally positive perceptions (Fidler, et al. 2008), deficits in early social communication in children with DS have in fact been reported (Fidler, Philofski, Hepburn \& Rogers, 2005).

One early social communication factor which is related to TD children's language development is joint attention, defined as a triadic interaction in which the child and caregiver focus on the same object or event (Tomasello, 1995). This behaviour emerges once infants progress to the period of intentional communication, when they develop a repertoire of behaviours serving specific pragmatic functions (obtaining an object, sharing attention with a caregiver) prior to using words. These behaviours, in turn, help build the child's social communication skills. Although joint attention behaviour is well documented as being concurrently and longitudinally related to language in TD infants, this is less clear in infants with DS, and requires investigation, particularly in relation to their expressive language deficits. Research studies have approached joint attention from two perspectives which complement each other: 1) joint attention skills, where the focus is on investigating the child's ability to use pointing or eye-gaze to share declarative communication functions related to sharing interest in objects and events as described above; and 2) joint engagement, which focuses on documenting the time the child and caregiver spend in joint attention episodes (Adamson, Deckner, Bakeman \& Romski, 2017).Another important social communication factor that is related to language development is the way caregivers behave and respond to their child, or maternal interactive style. For example, the transition from preintentional to intentional communication in infants is facilitated by their caregivers, via sensitive responding and support for early proto-conversations (Snow, 1977). Positive maternal input is known to be related to social, language and play development for TD children (Venuti, de Falco, Esposito, Zaninelli \& Bornstein, 2012; Venuti, de Falco, Esposito 
\& Bornstein, 2009). Currently, little is known about the association between maternal interactive style and language abilities in infants with DS. Each of these two factors (joint attention and maternal interactive style) will be discussed in turn.

\subsection{Joint attention (JA) and language development}

In the first few months of life, infants communicate with their caregivers in dyadic interactions. Between 6-12 months infants are able to follow a shift of gaze/head turn of an adult (Butterworth \& Jarrett, 1991). Within this period, infants also start to communicate to adults about objects. This move from dyadic to triadic interaction represents an important developmental milestone (Mundy, Kasari, Freeman \& Sigman, 1995). A JA episode can be introduced by the child, i.e. the child chooses an object or topic/event upon which the attention of the dyad is focused. This initiating of joint attention (IJA) is also referred to as 'commenting'. Alternatively, the caregiver chooses a toy/topic to which the infant's attention is then directed. This is referred to as 'responding to joint attention' (RJA) or 'attention following' (Mundy, Fox \& Card, 2003). The emergence of these skills represents the development of underlying social-cognitive processes that may provide a foundation for subsequent language development, such as the capacity for representational thought, and the idea that experiences can be shared (Mundy et al., 1995). Therefore, early words could be considered to replace non-verbal communication acts that have, until that stage, served the same pragmatic, referential, purpose (Wetherby et al., 1998). Furthermore, the use of these communicative skills often elicits verbal responses from caregivers, which increases the contingent linguistic input that the child receives (Yoder \& Warren, 1998).

IJA develops between 9-15 months of age; initially infants use gaze shifting to share an object/event with an adult and shortly after this they begin to point (Carpenter, Nagell \& Tomasello, 1998). IJA has been shown to account for unique variance in expressive language 
scores when controlling for initial chronological age, mental age, and expressive language (Mundy \& Gomes, 1998) in TD children. Although few studies have investigated IJA abilities in children with DS, the evidence available indicates that children with DS are as likely to initiate joint attention as are developmentally matched TD children (Sigman \& Ruskin, 1999). As in TD infants, IJA in infants with DS has been reported to be positively related to receptive and expressive language both concurrently and longitudinally (Mundy et al., 1995; Sigman \& Ruskin, 1999).

RJA emerges between 6-12 months in TD infants, and continues to develop until 18 months of age (Butterworth \& Jarrett, 1991; Morales et al., 2000). An important progression in RJA occurs between 12-18 months, when infants are able to follow another person's attention to a target that is outside their visual field (Butterworth \& Jarrett, 1991). This ability is believed to facilitate language development, as it enables children to avoid mapping errors during word learning because they are able to identify the intended referent of the speaker. There is evidence that differences in the ability to respond to joint attention are predictive of language after controlling for initial language status (Morales et al., 2000), and initial mental and chronological age (Mundy \& Gomes, 1998). Importantly, RJA has been found to be a unique predictor of language comprehension over and above chronological age, initial mental age, initial receptive language and IJA, and to be the only significant concurrent correlate of receptive, as well as expressive language in TD children (Mundy \& Gomes, 1998). Few studies report specific data on the ability of infants with DS to respond to joint attention. This is because many include infants with DS as part of a mixed aetiology group. The few existing studies have yielded mixed findings. On one hand, Mundy and colleagues reported that infants with DS (aged 12-36 months) had RJA deficits compared to mental age-matched TD peers and that RJA did not significantly correlate with expressive or receptive language (Mundy et al., 1995). On the other hand, Sigman and Ruskin (1999), using the same RJA 
measure (Gaze-Following Task of the Early Social Communication Scales - ESCS; Mundy, Hogan \& Doehring, 1996), found that children with DS (aged between 2 and 4 years) did not significantly differ from a mental age matched TD group. Further, in this latter study, RJA was significantly related to concurrent language ability (combining both receptive and expressive language) in the infants with DS, although it was not significantly related to gains in expressive language one year later. No predictors were found for receptive language. Using the same assessment (ESCS), a recent study by Mason-Apps et al., (2018) also reported that responding to joint attention and non-verbal mental ability at 18 months of age in children with DS predicted longitudinally language outcomes a year later.

\subsubsection{Time spent engaged in joint attention episodes and longitudinal language gains}

Further support that joint attention is related to language gains for children with DS comes studies which have investigated joint attention by focusing on time spent by child and caregiver om joint engagement. A significant positive correlation was found between the total number of seconds spent in joint attention episodes and receptive language gains for TD children (Harris, Kasari \&Sigman, 1996) who coded the number of joint attention episodes during a parent child interaction in children with DS and a TD group matched for mental age. Specifically, the average length of a joint attention episode positively correlated with receptive language gains for children with DS. Joint attention duration, frequency of episodes or average length of episodes were not significantly associated with gains in expressive language for either group. Receptive language development positively correlated with the frequency with which the caregiver maintained attention to child selected toys and to toys in general. However, a negative correlation was found between receptive language development and the frequency which the caregiver re-directed the child's attention from child selected toys and toys in general. 
More recently, Adamson, Deckner, Bakeman and Romski (2009) showed that symbol-infused supported joint engagement (the duration and frequency of episodes of coordinated joint attention), predicted longitudinally gains in receptive and expressive vocabulary, suggesting that periods on symbol-infused supported joint engagement when the child's focus is primarily on objects and their symbolic representations (rather than on the triadic interaction between child, parent/carer and object) may facilitate word acquisition. They did not find a relationship between joint attention behaviours and vocabulary development although they did not differ from typically developing children on the proportion of time spent in joint engagement episodes.

More recent research by Zampini, Salvi and D'Odorico (2015) investigated the link between time spent in joint attention episodes and vocabulary development for children with DS. They assessed joint attention and concurrent and longitudinal vocabulary of 18 infants with DS aged 24 months. When developmental age was controlled for, time spent in joint attention episodes was found to significantly correlate with receptive vocabulary at 24 months. Further analysis revealed that joint attention at 24 months was a significant predictor of receptive vocabulary at 30 months.

In summary, strong evidence is emerging that general joint attention skills and joint engagement are related to concurrent and longitudinal language outcomes for children with DS. What seems less clear is whether initiating and responding to joint attention skills individually are related to language skills in children with DS, and we examine each of these in turn in relation to language.

1.2.Maternal interactive style and language development

Previous research examining the relationship between maternal interactive style and child outcomes shows that a healthy, warm, nurturing and stable relationship between the 
caregiver and the child, along with contingent, prompt and appropriate caregiver reactions to child behaviours, has a positive impact on different aspects of a child's development including language (Landry, Smith, Swank, Assel \& Vellet, 2001). Positive maternal input is known to be related to social, language and play development for TD children (Venuti, de Falco, Esposito, Zaninelli \& Bornstein, 2012; Venuti, de Falco, Esposito \& Bornstein, 2009).

Sensitivity, defined as being attuned to infant signals, needs and direction of interest, and responding promptly and appropriately to them, is one dimension of maternal interactive style that has been associated with expressive and receptive language abilities (Leigh, Neivar \& Nathans, 2011). For example, maternal sensitivity at 9 months has been found to predict child language comprehension at 13 months and the development of language milestones when controlling for child behaviours at 9 and 13 months, such as vocalisations and play (Baumwell, Tamis-LeMonda \& Bornstein, 1997; Tamis-LeMonda, Bornstein \& Baumwell, 2001). Additionally, maternal sensitivity between 6 and 18 months has been found to positively correlate with expressive language skills at 30-36 months (Leigh, Nievar \& Nathans, 2011; Nozadi et al., 20013). Of particular relevance to the current study, maternal sensitivity is reported to be an important factor for fostering child language development when children are at risk of language delay (Hoff-Ginsberg, 1987), or with children who have lower language comprehension levels (Baumwell et al., 1997).

A positive relationship has also been reported between maternal warmth (e.g. expressing positive emotions, praising the child) and language ability (Clarke-Stewart \& Apfel, 1979; Landry, Smith, Swank, Assel \& Vellet, 2001; Steelman, Assel, Swank, Smith \& Landry, 2002). Both maternal sensitivity and warmth contribute to creating a stimulating social environment for the child, whereby they feel supported, guided, encouraged to engage in joint attention and motivated to learn and use appropriate language (Bigelow et al., 2010). 
In contrast, a lack of sensitivity and warmth has been found to be negatively correlated with language abilities (Landry, Smith, Miller-Loncar, \& Swank, 1997).

In the context of atypical development, few studies have investigated the relationship between parental interactive style and language development for children with DS. One early study by Crawley and Spiker (1983) reported that maternal interaction style, including sensitivity, was positively related to children's Mental Development Index (MDI) Scores on the Bayley Scales of Infant Development. However, the relationship between maternal sensitivity and language per se is not clear from this study because only general mental age scores were provided.

Aside from the question of whether the same relationship between parental interactive style and child language development applies in DS as in TD populations, the way in which parents of children with DS interact with them is important to establish. There is some evidence that mothers whose children have developmental delays interact differently with their children compared to mothers of TD children, and in particular they have been reported to act in a more directive, intrusive and controlling way (Glenn, Dayus, Cunningham \& Horgan, 2001; Pino, 2000). It may be also be that the mother is compensating for the child's lower level of cognitive development (Krakow \& Kopp, 1982), or that this is in response to challenging behaviour displayed by the child (Sterling \& Warren, 2014). Venuti et al. (2012) focused on functional features of maternal speech and found that parents of children with DS and children with Autism Spectrum Disorders (ASD) asked fewer questions during a parent child interaction and made fewer references to the environment but used more directive statements and more references to their child's actions. A positive association was found between frequency of maternal descriptions and child mean length of utterance, maternal references to the environment and mean length of utterance for the TD group only. No significant correlations between maternal language and child mean length of utterance was 
found for the children with DS or those with ASD. It was suggested that the parents of children with developmental disabilities tended to use a more 'directive' style defined by fewer questions and more directive statements. The fact that none of the features of maternal language were related to mean length of utterance for the children with DS suggests that the adopted 'directive' style may not have been facilitative of language development, and a more 'interactive style', i.e. mothers asking more questions and making more references to the environment may be preferable.

Nevertheless, a difference between how mothers of TD and mothers of children with DS interact with their offspring has not always been found. Gilmore, Cuskelly, Jobling and Hayes (2009) found no differences between how supportive or directive the mothers of children with DS were compared to mothers of mental age matched TD children. Similarly, Sterling and Warren (2014) reported that, although mothers of children with DS used more directive type behaviours (e.g. requests for behavioural compliance) compared to mothers of TD children, they did not increase the directive behaviours thought to hinder language development (e.g. redirecting the child's attention). However, in the same study, Sterling and Warren found that mothers of children with DS differed from mothers of TD children in that they used facilitative behaviours more frequently with older than with younger children. Examples of facilitating behaviours included giving verbal praise in response to a child's action, or giving a verbal interpretation of something the child said. The reverse was seen in the TD group whereby mothers used more facilitative behaviours with younger children. The authors suggest that the mothers of children with DS adapted their style to meet the linguistic needs of their child. Historically, this has been reported for mothers of children with developmental delays (Marfo, 1990).

There is also some emerging evidence that parental responsiveness to children's gestures, and importantly, translating their gestures into words, may facilitate vocabulary 
acquisition in children with DS (Dimitrova et al., 2016). The parents of children with DS, just like the parents of the TD children, responded verbally to their children and translated an equally high number of their children's gestures into words. However, it should be noted that the children with DS in this study gestured less than their TD peers, thus limiting the parental opportunities to provide translations for their gestures.

In summary, little is known about the development of JA skills in infants with DS, and more research is needed to investigate whether these skills may be related to language. Also, it is not yet clear what the relationship may be between maternal interactive style and language development in infants with DS since, to our knowledge, no previous research has considered a link between maternal interactive style and concurrent language skills for this population. There are some suggestions that the behaviour of mothers of children with DS may be different from that of mothers of TD children, specifically, that the mothers of children with DS may be more directive and intrusive during interactions. Given the evidence that these two social communication factors (JA and maternal interactive style) are related to language development in TD children, investigating the relationship between these factors and language in DS is a good starting point for understanding some of the language delays in DS.

\subsection{The current study}

The aim of the current study was to investigate the relationship between: 1) JA and concurrent language skills, and 2) maternal interactive style and concurrent language skills in children with DS compared to TD children. Our study uniquely combines these two social factors in the same study and in children with DS: JA (where the child initiates and responds to the parent) and maternal interactive style (focusing on how the parent initiates and responds to the child) and the relationship of these two social factors and language. The study 
addresses the following questions: 1) are there between group differences with regard to JA skills and maternal interactive style? 2) is the relationship between JA and concurrent language status, and maternal interactive style and concurrent language status different in the DS and TD groups? We addressed these questions by comparing JA skills (IJA and RJA) and maternal interactive style (sensitivity and positive expressed emotion) of two groups of infants: a group with DS and a TD group with equivalent NVMA and overall language ability.

Predictions

Based on previous research, which has shown a positive relationship between JA and language in TD and DS populations (e.g. Mundy et al. 1998), we predicted that JA would be related to concurrent language abilities in both groups. Since previous research has found a relationship between parental interactive style and language in TD children, we expected that parental interactive style would be related to concurrent language in the TD group. In comparison, due to a lack of past research on the relationship between parental interactive style and language development in DS, we are not able make a prediction about this group. Based on previous research on parental interactive style with infants with DS, we predicted that the parents of the DS group of infants may have a different interactive style compared to the parents of the TD infants.

\section{Method}

\subsection{Participants}

Fifty-five children aged between 9 and 23 months were recruited for the study. Ethical approval was obtained from the University of [removed for review] Research Ethics committee. Written informed consent was obtained from parents. Thirty typically developing (TD) monolingual English children (14 girls, 16 boys) were recruited via the University of 
[removed for review] Child Development Group database. The mean age was 10 months (315 days, range: 281-335 days). There were 25 children with Down syndrome (DS) (11 girls, 14 boys) who were recruited through DS charities or support groups. Their mean age was 19 months (592 days, range: 526-710 days). Two of the infants with DS were exposed to another language in addition to English, with English being the dominant language for both. The two groups did not differ significantly on non-verbal mental age (NVMA; assessed using the Mullen's Scale of Early Learning; Mullen, 1995) (TD 13.5 months and DS 14 months, TD $\mathrm{Mdn}=24.37$ and DS $\mathrm{Mdn}=32.36: \mathrm{U}=266, \mathrm{Z}=-1.858, \mathrm{p}=.063, \mathrm{r}=-.25)$ and they did not differ on total language scores as assessed on the Pre-school Language Scales 4 (TD Mdn $=38.48$ and DS Mdn =36.73: U=306, $\mathrm{Z}=-1.18, \mathrm{p}=.240, \mathrm{r}=-.16) \quad$ (Zimmerman, Steiner \& Pond, 2002).

Parental education level ranged from GCSE (General Certificate of Secondary Education) to a post-graduate degree with the majority educated to degree level or higher (67\%). There were no significant differences between the two groups for maternal education. In terms of occupation, the majority of the mothers of children with DS were not currently working $(62.5 \%)$, one mother was on maternity leave, and the remaining were employed (33\%). The mothers of TD children were mostly split between not currently working (25\%), employed (50\%) and on maternity leave (29\%). All the fathers in both groups were either employed full time or self-employed.

\subsection{Measures}

Maternal measures

To assess maternal interactive style, a five minute, free-play mother-child interaction session was video-recorded from an observation lab. Parents were instructed to play normally with their child as they would at home and to use any of the available toys. The interaction 
was later coded using the parent-child interaction coding scheme by Murray and Karpf (2000) (which is an adaptation from Stein, Woolley, Cooper \& Fairburn ,1994; Skuse, Wolke \& Reilly, 1992; Wolke, Skuse \& Mathisen, 1990). for maternal positive expressed emotion (PEEM) and an adaptation from Wolke, Skuse and Mathiasen (1990), and Skuse, Wolke and Reilly (1992) for sensitivity (see Appendix for full coding scheme) and PEEM was coded by counting how many times the mother praised or was affectionate towards the child (e.g., saying 'well done' after the child completed an activity). Sensitivity, which reflects how well the mother responded to the infant's cues versus a focus on her own wishes, was coded using a 5 point scale with 1 being highly insensitive and 5 highly sensitive. Behaviours such as how the mother positioned herself in relation to the infant, if she let the infant explore the environment, and if she provided help when needed were also included in this scale (please see appendix for coding scheme). Two coders were trained using materials provided by Murray and Karpf; $20 \%$ of the data were independently coded by the first author and a research assistant who was not aware of the research hypotheses, and yielded good estimates of inter-rater reliability, $\kappa=.737, \mathrm{p}<.001, \mathrm{CI}=-0.59-0.88$.

\section{Child measures}

Initiating and responding to joint attention (IJA, RJA) were assessed using the abridged version of the Early Social Communication Scales (ESCS; Mundy et al. 1996). The assessment was video-recorded and coded after the session. The researcher used three windup toys, three mechanical toys and a book. Four posters were placed to the left and right $\left(90^{\circ}\right)$ and behind left and right $\left(180^{\circ}\right)$ of the child. To assess IJA, the researcher initiated six sets of three trials whereby she activated a wind-up or mechanical toy in front of the child for 6 seconds and then gave the child the deactivated toy for 10 seconds. The following behaviours were coded as the child IJA with the researcher: eye contact, alternating eye contact, pointing, pointing with eye contact and showing the researcher the toy. Eye contact and 
alternating eye contact were scored as 'lower level' behaviours whereas pointing and showing were 'higher level' behaviours. If 'showing' an object the infant was require to make simultaneous eye contact with the researcher, whereas 'pointing' could be coded with or without eye contact.

RJA was scored during a 'proximal point' and 'gaze following task'. For the proximal point task, the researcher pointed to six pictures in a book on consecutive pages and counted how many times the child looked at the selected picture, giving a score out of six. For the gaze following task, the researcher pointed to the posters placed around the child. Whilst pointing at the poster the researcher would say the child's name three times. Coding from the video documented the number of occasions in which the child turned and looked at the poster, giving a total score out of eight. The scores from these two tasks were then combined to give a percentage total score for RJA. Two coders independently coded $20 \%$ of the sample and achieved excellent agreement across all indices, $r(12)=.973, \mathrm{p}<.001$.

Receptive and expressive language was assessed using the Preschool Language Scales (PLS)-4 (Zimmerman, Steiner, \& Pond, 2002), a standardised language assessment for children between one month and 6 years 11 months. The PLS has been used in multiple research studies with children with DS (Bird et al. 2005; Wright, Kaiser, Reikowsky \& Roberts, 2013). Sensitivity and specificity for the subscales and combined scores range from .77 to .92 . The test was standardised using a sample of 1,564 children.

To obtain an estimate of NVMA, the Mullen Scale of Early Learning (MSEL; Mullen, 1995) was used. This is a standardised assessment which includes measures of the child's fine motor, gross motor and visual reception. As indicated by Wetherby et al. (2004), the fine motor and visual reception scores were averaged into a composite score. The scale has been previously used with children with DS (Sterling \& Warren, 2014; Wright et al., 2013;). 
Testretest coefficients between .71 and .96 have been found. The concurrent validity has been measured using the Bayley Scales of Infant Development and the PLS.

\subsection{Procedure}

The testing session took approximately one hour per child to complete. The majority of participants were tested in a children's lab at the University of [removed for review]; those children whose parents were unable to travel were tested in the participants' home. The participant sat on their mother's lap opposite the researcher at a table during the testing session (apart from the free play). Participants were assessed using the receptive and expressive components of the PLS-4 (Zimmerman., et al., 2002) the gross motor, fine motor and visual reception subscales of the MSEL (Mullen, 1995) and the abridged version of the ESCS (Mundy et al., 1996) with tasks assessing IJA and RJA. Parents were asked to complete a demographic questionnaire relating to their highest level of education and current employment. At the end of the testing session, the parents were asked to engage in a 5-minute free play interaction with their child, as they would at home. A box of toys was provided which included stacking blocks, a ball, books, a telephone, cars, a Mr Tumble toy and various wind-up animals. During this play interaction, the tester left the room.

\subsection{Data analysis}

First between group comparisons were carried out using independent t-tests and Mann Whitney U tests. A correlation analysis was then used to see if any of the predictor variables correlated with language scores for either group. Finally, a multiple linear hierarchical regression was used to see if and of the predictor variables were significant predictors of language scores for either group controlling for age, NVMA and group.

\section{Results}

\subsection{Between group comparisons}


Table 1 shows the means and standard deviations for JA, maternal interactive style and language. As some of the variables were not normally distributed, Mann Whitney U tests were used to investigate differences between the groups, and effect sizes were calculated. A Bonferroni correction was applied to control for multiple comparisons and the significance level was .004 , corrected to control for type I error. Effect sizes were calculated by dividing the $\mathrm{Z}$ score by the square-root of the total sample size. No significant differences were found between the two groups for total RJA, gaze following task, proximal point task or IJA. Similarly, no differences were found for parental interactive style. No differences were found for total language scores or expressive communication, however, a significant difference was found for auditory comprehension, with the DS group scoring significantly higher $(\mathrm{Mdn}=20)$ than the TD group (Mdn=17.5): $\mathrm{U}=192.5, \mathrm{Z}=-3.137, \mathrm{p}=.002$. This reflects the fact that the DS sample were older and that their receptive language is generally higher than their expressive language (Fidler \& Nadel, 2007). 
Table 1: Descriptive statistics for language, JA and maternal interactive style in DS and TD (raw scores)

\begin{tabular}{llllll} 
Variable & \multicolumn{5}{c}{$\mathrm{M}(\mathrm{SD})$} \\
& $\mathrm{DS}(\mathrm{n}=25)$ & $\mathrm{TD}(\mathrm{n}=30)$ & $\mathrm{U}$ & $\mathrm{Z}$ & $\mathrm{r}$ \\
\hline Age in days & $315.33(12.07)$ & $592.56(44.21)$ & & & \\
RJA & $42.15(23.4)$ & $45.55(23.92)$ & 345 & -.508 & -.07 \\
Gaze follow & $32.29(21.47)$ & $24.58(21.14)$ & 287.5 & -1.29 & -.17 \\
Book point & $53.31(34.68)$ & $70.27(35.85)$ & 258 & -2.02 & -.27 \\
IJA & $19.73(11.94)$ & $17.76(13.12)$ & 268 & -.971 & -.13 \\
PEEM & $5.33(4.71)$ & $3.52(2.57)$ & 215.5 & -1.05 & -.14 \\
Sensitivity & $2.95(1.2)$ & $3.04(1.24)$ & 256.5 & -.136 & -.02 \\
PLS AC & $19.52(2.6)$ & $17.53(1.01)$ & 192.5 & $-3.14 * *$ & -.42 \\
PLS EC & $18.96(2.78)$ & $19.2(2.01)$ & 324 & -.876 & -.12 \\
PLS TL & $38.48(4.74)$ & $36.73(2.53)$ & 306 & -1.18 & -.16
\end{tabular}

Note. RJA - responding to joint attention, IJA - initiating joint attention, PEEM - positive expressed emotion, PLS AC - auditory component, PLS EC - expressive component, PLS $\mathrm{TL}$ - total language, $\mathrm{U}=$ Mann Whitney $\mathrm{U}, \mathrm{r}=$ effect size, $0.1=$ small size, $0.3=$ medium size, $0.5=$ large size (Field, 2009), **p<.01

3.2 Associations between child and maternal variables, and children's concurrent language scores

To investigate the association between IJA, RJA, NVMA (child variables), PEEM, sensitivity (maternal variables) and concurrent language status, we conducted Spearman's correlations within each group. These are shown in tables 2 and 3 below. 
Table 2: Correlations between language, nonverbal mental age, JA and maternal interactive style for the DS group (Spearman's rho):

\begin{tabular}{|c|c|c|c|c|c|c|c|c|}
\hline & NVMA & RJA & IJA & PEEM & Sensitivity & $\mathrm{AC}$ & $\mathrm{EC}$ & $\mathrm{TL}$ \\
\hline Age in days & $.415^{*}$ & .126 & $.460 *$ & -.204 & -.214 & .257 & .012 & .201 \\
\hline NVMA & & .317 & .291 & -.025 & .121 & $.554 * *$ & .303 & $.494 *$ \\
\hline RJA & & & .223 & -.087 & .151 & $.528 * *$ & $.512 * *$ & $.597 * *$ \\
\hline IJA & & & & -.344 & .080 & .298 & .303 & .375 \\
\hline PEEM & & & & & $.454 *$ & -.222 & -.111 & -.205 \\
\hline Sensitivity & & & & & & .054 & .244 & .137 \\
\hline $\mathrm{AC}$ & & & & & & & .396 & $.883 * * *$ \\
\hline $\mathrm{EC}$ & & & & & & & & $.743 * * *$ \\
\hline
\end{tabular}

Note. $* \mathrm{p}<.05, * * \mathrm{p}<.01, * * * \mathrm{p}<.001, \mathrm{NVMA}-$ non-verbal mental age, RJA- responding to joint attention, IJA - initiating joint attention, PEEM - positive expressed emotion, AC auditory comprehension, EC - expressive communication, TL - total language PLS 
Table 3: Correlations between language, nonverbal mental age, JA and maternal interactive style for the TD group (Spearman's rho)

\begin{tabular}{|c|c|c|c|c|c|c|c|c|}
\hline & NVMA & RJA & IJA & PEEM & Sensitivity & $\mathrm{AC}$ & $\mathrm{EC}$ & $\mathrm{TL}$ \\
\hline Age in days & .112 & -.121 & -.136 & .159 & .083 & .170 & $.376^{*}$ & .319 \\
\hline NVMA & & -.145 & .012 & .014 & -.134 & .218 & .033 & .115 \\
\hline RJA & & & -.308 & .253 & .052 & -.022 & .182 & .131 \\
\hline IJA & & & & -.254 & .315 & .003 & -.020 & .018 \\
\hline PEEM & & & & & .117 & $.460 *$ & $.607 * *$ & $.643 * *$ \\
\hline Sensitivity & & & & & & -.165 & .101 & .011 \\
\hline $\mathrm{AC}$ & & & & & & & $.449 *$ & $.704 * * *$ \\
\hline $\mathrm{EC}$ & & & & & & & & $.927 * * *$ \\
\hline
\end{tabular}

$* \mathrm{p}<.05,{ }^{*} \mathrm{p}<.01 * * * \mathrm{p}<.001, \mathrm{NVMA}-$ non-verbal mental age, RJA- responding to joint attention, IJA - initiating joint attention, PEEM - positive expressed emotion, AC - auditory comprehension, EC-expressive communication, TL - total language PLS

As tables 2 and 3 show, NVMA and RJA significantly correlated with concurrent language scores in the DS group, whereas only PEEM significantly correlated with language in the TD group. However, since a negative trend emerged between PEEM and language for the DS group this was investigated further. We performed a median split to find those children with DS who had the lowest language scores. This resulted in identifying a subset of ten children with a total language score of 37 or lower. A moderate association was found which approached significance $(\mathrm{r}(10)=-.571, \mathrm{p}=.085)$, suggesting that the lower the children's language scores were, the more PEEM the parents in the DS group used.

Next, to assess how much variance in total language scores could be explained by the predictor variables, a hierarchical regression was carried out. A power analysis revealed that 
a sample size of 49 was needed to achieve a large effect size with a $p$ value of .05 based on seven predictors. Total language was used as the dependent variable and in the first model age, NVMA and group were entered as predictor variables. In the second model RJA and PEEM were added. Two interaction variables were then computed involving group and RJA and group and PEEM and these were put into the third model (see table 4).

Table 4: Results from hierarchical regression analysis assessing association between joint attention, positive expressed emotion and total language scores

\begin{tabular}{|c|c|c|c|c|c|c|c|c|c|}
\hline \multirow[b]{2}{*}{ Variable } & \multirow[b]{2}{*}{ B } & \multicolumn{2}{|c|}{ Model 1} & \multicolumn{3}{|c|}{ Model 2} & \multicolumn{3}{|c|}{ Model 3} \\
\hline & & SE & $\beta$ & $\mathrm{B}$ & SE & $\beta$ & B & SE & $\beta$ \\
\hline Age & .005 & .004 & .199 & -.008 & .018 & -.286 & -.011 & .016 & -.410 \\
\hline NVMA & .406 & .233 & .257 & .325 & .223 & .206 & .239 & .202 & .151 \\
\hline \multicolumn{4}{|l|}{ Group } & 3.712 & 5.013 & .472 & 2.474 & 5.062 & .315 \\
\hline \multicolumn{4}{|l|}{ RJA } & .070 & .023 & $.404 * *$ & -.115 & .066 & -.664 \\
\hline \multicolumn{4}{|l|}{ PEEM } & -.020 & .146 & -.019 & 1.354 & .540 & $1.289 *$ \\
\hline \multicolumn{4}{|c|}{ Group*RJA } & & & & .121 & .042 & $1.321 * *$ \\
\hline \multicolumn{4}{|c|}{ Group*PEEM } & & & & -.769 & .300 & $-1.451 *$ \\
\hline \multicolumn{2}{|l|}{$\mathrm{R}^{2}$} & \multicolumn{3}{|l|}{.132} & \multicolumn{3}{|l|}{.295} & \multicolumn{2}{|l|}{.471} \\
\hline \multicolumn{2}{|c|}{$\mathrm{F}$ for $\mathrm{R}^{2}$ change } & \multicolumn{3}{|c|}{$3.268 *$} & \multicolumn{3}{|l|}{$3.087 *$} & \multicolumn{2}{|c|}{$6.336 * *$} \\
\hline
\end{tabular}

Key. $* \mathrm{p}<.05, * * \mathrm{p}<.01, \mathrm{~B}=$ unstandardized Beta, $\mathrm{SE}=$ standard error, $\beta=$ standardised Beta

The first model, which used CA, and NVMA as predictors, was significant $F(2,43)=$ 3.268, $\mathrm{p}=.048, \mathrm{R}^{2}=.132$. The second model, which added group, RJA and PEEM, was also significant $\mathrm{F}(5,40)=3.349, \mathrm{p}=.013, \mathrm{R}^{2}=.295$ and accounted for an additional $16.3 \%$ of variance ( $\mathrm{R}$ square change). The final model, which included also the two interaction 
variables, was also significant $\mathrm{F}(7,38)=4.841, \mathrm{p}=.001, \mathrm{R}^{2}=.471$ and added a further $17.6 \%$ of variance.

In the first model, neither of the independent variables (age and NVMA) were significant predictors. In the second model, only RJA was a significant predictor: $\beta=.404, \mathrm{t}=$ 2.971, $\mathrm{p}=.005$. In the final model, when the interaction variables were added, RJA was no longer a significant predictor $(\mathrm{p}=.089)$. PEEM, however, was a significant predictor in this model: $\beta=1.289, \mathrm{t}=2.510, \mathrm{p}=.016$, as were the interaction variables group*RJA: $\beta=1.321$, $\mathrm{t}=2.851, \mathrm{p}=.007$ and group*PEEM: $\beta=-1.451, \mathrm{t}=-2.560, \mathrm{p}=.015$. This suggests that the influence of both RJA and PEEM on language scores was affected by which group participants were in, and this is further demonstrated in figures 1 and 2 below.

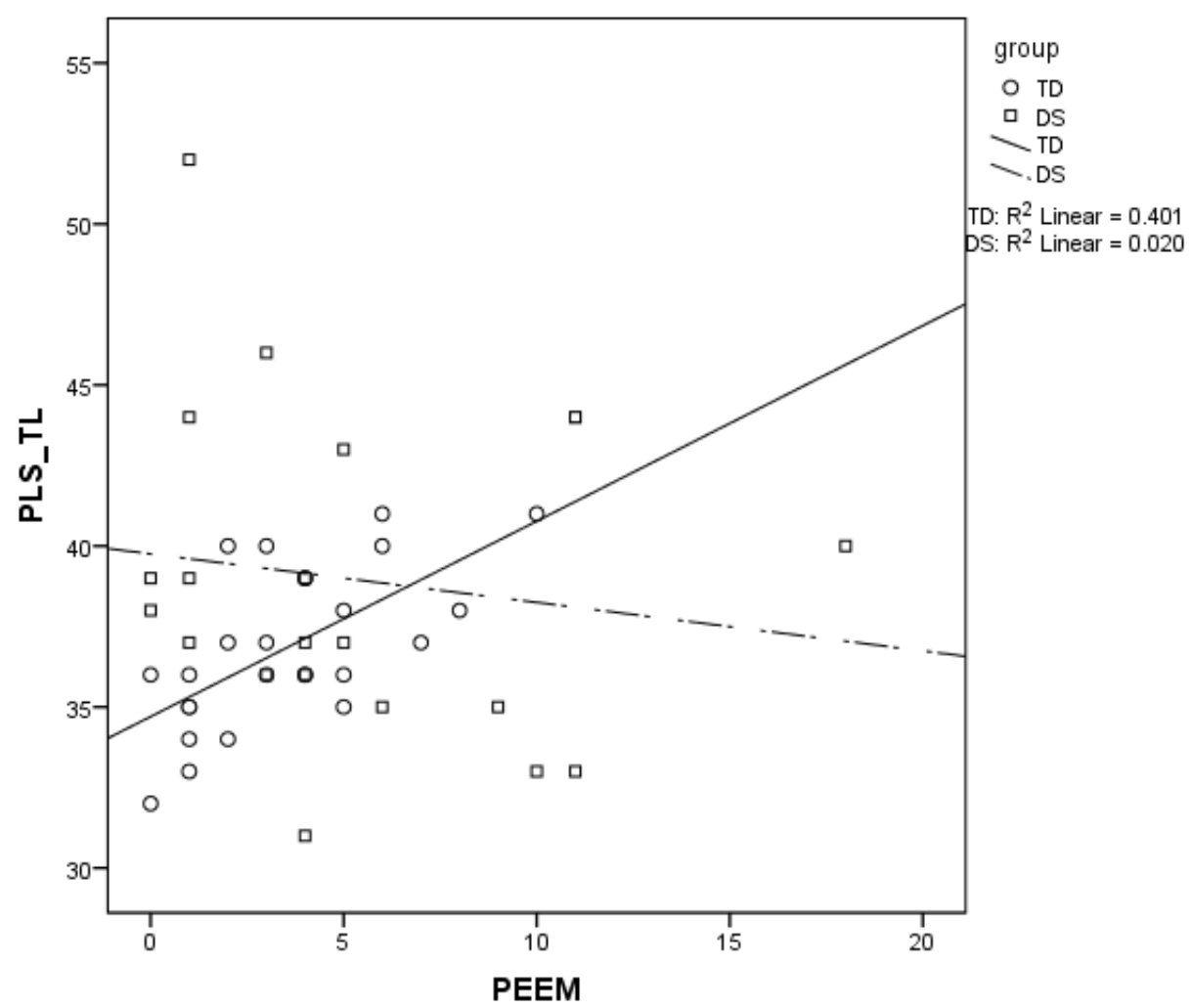

Figure 1: Scatterplot for PEEM and total language showing regression line for group 


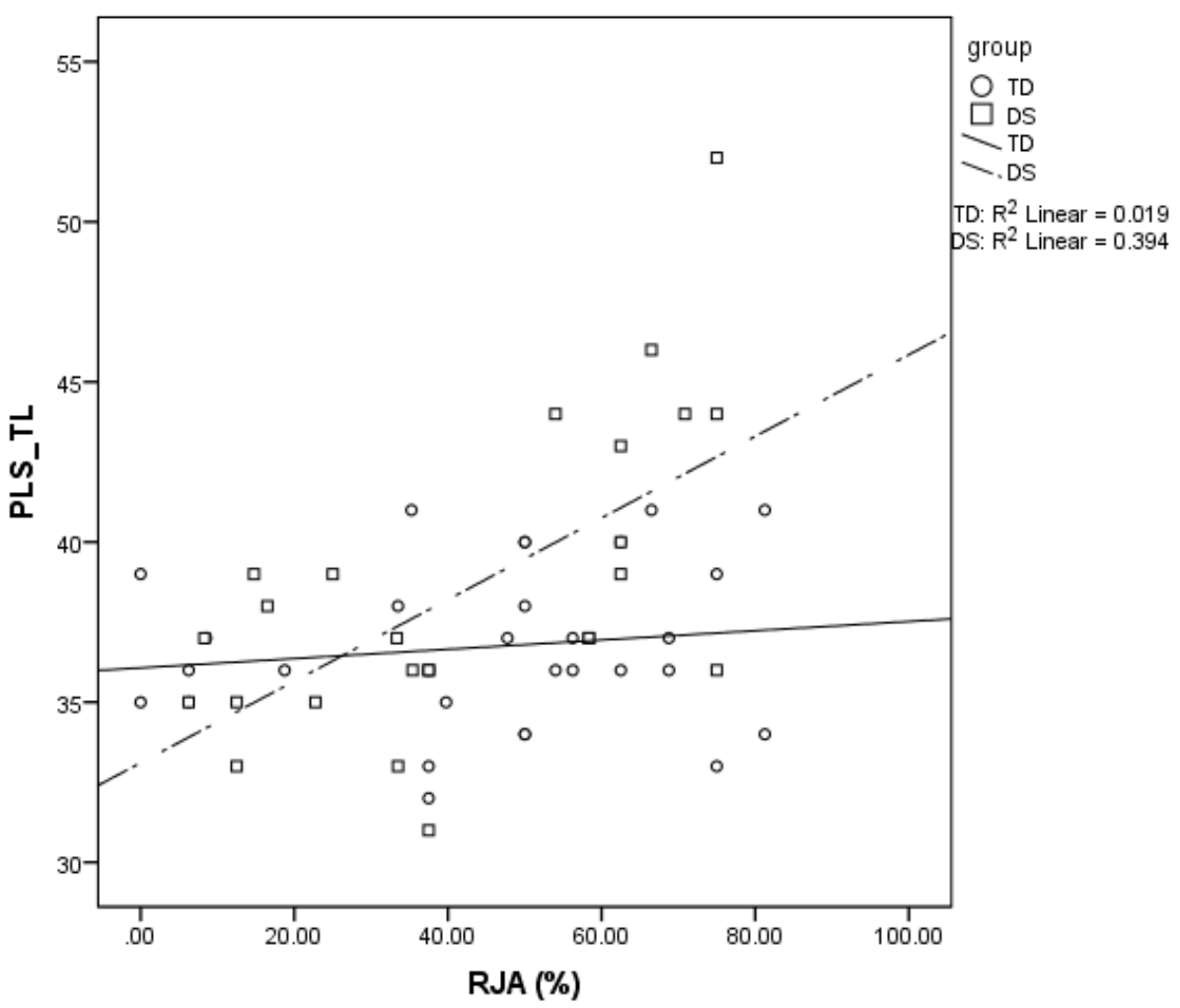

Figure 2: Scatterplot for RJA and total language showing regression line for group

The figures demonstrate the interaction between group and the predictor variables. In the TD group PEEM has a positive relationship with total language, suggesting that higher levels of PEEM are associated with higher total language scores. This relationship is not evident for the DS group. The reverse is seen for RJA, whereby a positive association between RJA and total language is found in the DS, but not the TD group.

\section{Discussion}

The main findings of this study are: 1) there were no significant differences with regard to maternal interactive style (sensitivity and positive expressed emotion) between the mothers of infants with DS and mothers of TD infants. There were also no differences with regards to IJA and RJA for infants in either group; 2) RJA was significantly related to concurrent language skills for children in the DS group but not for TD children; 3) Positive 
expressed emotion was significantly related to language for children in the TD group but not for the children with DS. These findings will be discussed below.

Our first research question focused on whether there would be differences between the DS and TD groups in terms of parental interactive style (positive expressed emotion and sensitivity) and JA (IJA and RJA). Based on previous research (Glenn et al. 2001), we predicted that the mothers of infants with DS would display different behaviours when interacting with their infants than the mothers of TD infants. However, no significant differences were found between the two groups in terms of how sensitive or positive mothers were during interactions. This differs from earlier research which suggests that parents of children with DS are less sensitive and more intrusive than parents of TD children (Glenn et al. 2001). Our findings are in line with Gilmore et al. (2009)'s study, who also found no differences in interaction styles between mothers of TD children and mothers of children with DS. Also, our findings are in line with recent work by Sterling and Warren (2014) who reported that, although mothers of children with DS used certain directives more frequently than mothers of a group of age matched TD children, they rarely used intrusive directives, i.e. redirecting their child's attention. Our findings and those of Gilmore et al., (2009) and Sterling and Warren (2014) suggest that there may have been a change over time in parental behaviours regarding their interaction with children with DS, which may be the result of more information being available about DS in general and especially about parent-child interaction strategies.

With regards to JA, our findings are in line with Sigman \& Ruskin (1999), who also found no differences between the TD and DS groups on the gaze-following task of the ESCS) and that RJA was significantly related to concurrent language skills. However, our findings differ from Mundy et al.'s (1995) study, which reported a difference between children with DS and TD children in terms of RJA and did not find a significant concurrent relationship 
between RJA and language. This may be due to the sample used in Mundy et al.'s study which included children with a much wider age range (12-36 months in comparison to 17-23 months in our study). As some of the infants with DS were twice the chronological age of the infants in our study, it is possible that some of the infants with DS in the Mundy et al.'s study may have reached a 'ceiling' given the fact that infant JA skills consolidate in the period between 12 and 18 months of age (Morales et al., 2000) and may no longer be associated with language development. Furthermore, previous research has highlighted that individuals with DS are sociable and seek social interaction. For example, Adamson, Deckner \& Bakeman (2010) found that the interest of individuals with DS in a researcher increased and strengthened across a year, whereas TD children's interest decreased. Furthermore, interest in the adult and new objects was found to be a significant predictor of joint engagement. This may indicate that early social communication skills are a relative strength for individuals with DS, as they are motivated to engage in social interactions. Given what is already known about the existence of a positive relationship between symbol-infused supported joint engagement and language (Adamson et al., 2009) and also the fact that studies on other developmental disorders, such as autism have shown that it is responding to joint attention rather than initiating which predicts variation in early word learning (Sigman \& Ruskin, 1999; Sullivan et al., 2007), it is not surprising that we find responding to joint attention and concurrent language outcomes related in infants with DS.

Our second research question focused on whether JA or maternal interactive style would be related to language development for either group. RJA was found to be a significant predictor of total language scores as measured by the PLS-4 for participants in the DS group in a model accounting for chronological age, NVMA and positive expressed emotion. By contrast, IJA was not significantly correlated with language for either group. The reason RJA was a significant predictor and not IJA may be because, at this age, the children were not 
initiating joint attention very often (see table 1), suggesting that interactions were mostly adult initiated. The ability to initiate JA starts to develop at around 9 months for TD children (Bakeman \& Adamson, 1984). This would suggest that the infants in our sample were starting to develop this skill as they were between 9 and 11 months of age. In comparison, the ability to respond to JA starts developing at a much earlier age (around 2-6 months, Scaife \& Bruner, 1975).

An unexpected finding was that JA skills did not show a significant association with language abilities in the TD group. This is different from several studies which have shown that both IJA and RJA predict concurrent language abilities (Carpenter et al. 1998). However, all these studies were either with older children, and/or used a different method to assess JA, and this may explain why we did not obtain the same results. The TD children in our sample were 9-11 months and the previous research in this area which uses a similar age range reports a longitudinal relationship of JA and language, rather than a concurrent one (e.g. Morales et al., 2000). Since we used such a small age range there was not much variability between scores. Furthermore, although the groups in our study did not differ on NVMA and general language abilities, and there were no significant differences for JA, the DS group showed greater variability in scores for JA. Since the DS group was twice as old as the TD group, they would have been exposed to more cumulative social interaction than the TD group, which may also explain why a relationship between JA and language was found in the DS group but not the TD group. We would predict that if we were to look at this TD group when they are around 6 months older we would very likely see a relationship between JA and language.

Regarding the maternal measures, there was a significant relationship between maternal positive expressed emotions and total language scores in the TD group only. The regression analysis confirmed that positive expressed emotion was a significant predictor of 
total language scores for the TD children controlling for the children's chronological and NVMA, and RJA. This is in line with previous research which has found a relationship between positive expressed emotion and language development (Clarke-Stewart \& Apfel, 1979). In the DS group, the maternal variables investigated in this study were not concurrently related to the children's language abilities. Observation of the interactions suggested that parents of TD children tended to praise children after they had completed a goal (e.g. stacking blocks) while parents of the children with DS would often praise the child even when they had not completed a goal/task. It was also the case that some parents used a lot of positive expressed emotion with their children with DS who had low scores on the language measures and this was confirmed by the correlation analysis which focused on those children with the lowest language scores. This parental behaviour may reflect the parents' efforts to encourage and motivate their child when they experienced difficulties. Indeed, it seemed that the more language delayed the child with DS was, the more positive expressed emotion the mother showed in her interactions. The correlation between positive expressed emotion and total language in the DS group for those with the lowest scores was negative and approaching significance, which may suggest that parents in this group may have been using positive expressed emotion to encourage their child with more limited language skills to get involved in the interaction.

It is not uncommon for language acquisition to be different in children with genetic disorders vs. TD children (Farran \& Karmiloff-Smith, 2012). For example, in children with Williams syndrome (also a developmental genetic disorder), the association between social interaction skills, social referencing and language is different from that which is found in TD children (Laing et al., 2002). The results of our study lead to the hypothesis that different social-communication factors are associated with language skills in infants with DS, at least 
in the time period between 17 and 22 months of age compared to TD infants of similar nonverbal and general language abilities.

\subsection{Conclusions and further research}

The results suggest that, at this stage of cognitive development (chronological age1822 months and non-verbal mental age $=14$ months), responding to joint attention is an important factor in language development for children with DS. In our study, we did not measure time spent in joint engagement episodes. If we did, we would expect to find a similar relationship between time spent in joint engagement episodes and language, because there is growing evidence to suggest this is the case both in typically developing children and in children with DS (Adamson, Bakeman \& Deckner, 2004; Adamson et al., 2009). In comparison, a maternal factor, specifically positive expressed emotion, was found to be related to concurrent language scores for TD children. A next step would be to conduct a longitudinal study to find out if these same factors are related to later language, or whether the predictors change with age. Based on previous research, as the children get older, we would expect initiating joint attention to be related to language development. Also, our study used a measure of language which, unlike other studies, does not only focus on vocabulary as a measure of language but assesses general language skills. If we had used a measure of vocabulary only, as done in other studies (Adamson et al., 2009; Zampini et al., 2015), we would expect to find similar finding because there is generally a positive relationship between measures of vocabulary and general language skills. Finally, the results have implications for early intervention. If RJA at this age is important for language development for children with DS then it may be possible to implement early interventions at this stage focusing on RJA with a view to enhancing later language outcomes. 
Acknowledgements

We would like to thank the ESRC, DownsEd International and the University of [removed for review] for their financial support for this project. We would also like to thank all the charities which helped with the recruitment of participants as well as all the parents and children for taking part in the study.

References

Adamson, L. B., Bakeman, R., Deckner, D. F., \& Romski, M. (2009). Joint engagement and the emergence of language in children with autism and Down syndrome. Journal of Autism and Developmental Disorders, 39(1), 84.

Adamson, L. B., Bakeman, R., \& Deckner, D. F. (2004). The development of symbol-infused joint engagement. Child Development, 75, 1171-1187.

Bakeman, R., \& Adamson, L. B. (1984). Coordinating attention to people and objects in mother-infant and peer-infant interaction. Child development, 1278-1289.

Baumwell, L., Tamis-LeMonda, C. S., \& Bornstein, M. H. (1997). Maternal verbal sensitivity and child language comprehension. Infant Behavior and Development, 20(2), 247258.

Berglund, E., Eriksson, M., \& Johansson, I. (2001). Parental reports of spoken language skills in children with Down syndrome. Journal of Speech, Language, and Hearing research, 44(1), 179-191.

Bigelow, A. E., MacLean, K., Proctor, J., Myatt, T., Gillis, R., \& Power, M. (2010). Maternal sensitivity throughout infancy: Continuity and relation to attachment security. Infant Behavior \& Development: $33,50-60$. 
Bird, E. K. R., Cleave, P., Trudeau, N., Thordardottir, E., Sutton, A., \& Thorpe, A. (2005). The language abilities of bilingual children with Down syndrome. American Journal of Speech-Language Pathology, 14(3), 187-199.

Butterworth, G., \& Jarrett, N. (1991). What minds have in common is space: Spatial mechanisms serving joint visual attention in infancy. British journal of Developmental Psychology, 9, 55-72.

Carpenter, M., Nagell, K., Tomasello, M., Butterworth, G., \& Moore, C. (1998). Social cognition, joint attention, and communicative competence from 9 to 15 months of age. Monographs of the Society for Research in Child Development, 63, i-174.

Chapman, R. S., \& Hesketh, L. J. (2000). Behavioural phenotype of individuals with Down syndrome. Mental Retardation and Developmental Disabilities Research Reviews, 6, 84-95.

Chapman, R., \& Hesketh, L. (2001). Language, cognition, and short-term memory in individuals with Down syndrome. Down Syndrome Research and Practice, 7(1), 1-7.

Chapman, R.S. (2003). Language and communication in individuals with Down syndrome. (pp. 1-34) In L. Abbeduto (Ed.), International Review of Research in Mental Retardation: Language and Communication, vol. 27. Academic Press.

Clarke-Stewart, K. A., \& Apfel, N. (1979). Evaluating parental effects on child development. In L. S. Schulman (Ed.), Review of Research in Education. (pp. 47- 119). Itasca, IL: Peacock.

Crawley, S. B., \& Spiker, D. (1983). Mother-child interactions involving two-year-olds with Down syndrome: A look at individual differences. Child development, 1312-1323. 
Dimitrova, N., Ozcaliskan, S., \& Adamson, L. (2016). Parents' translations of child gesture facilitates word learning in children with autism, Down syndrome and typical development. Journal of Autism and Developmental Disorders, 46 (1), 221-231

Farran, E. K., \& Karmiloff-Smith, A. (Eds.). (2012). Neurodevelopmental disorders across the lifespan: A neuroconstructivist approach. Oxford: Oxford University Press.

Fidler, D. J., Philofsky, A., Hepburn, S. L., \& Rogers, S. J. (2005). Nonverbal requesting and problem-solving by toddlers with Down syndrome. American Journal on Mental Retardation, 110, 312-322.

Fidler, D. J., \& Nadel, L. (2007). Education and children with Down syndrome: neuroscience, development, and intervention. Mental Retardation and Developmental Disabilities Research Reviews, 13, 262-271.

Fidler, D. J., Most, D. E., Booth-LaForce, C., \& Kelly, J. F. (2008). Emerging social strengths in young children with Down syndrome. Infants \& Young Children, 21(3), 207-220.

Galeote, M., Sebastián, E., Checa, E., Rey, R., \& Soto, P. (2011). The development of vocabulary in Spanish children with Down syndrome: Comprehension, production, and gestures. Journal of intellectual and developmental disability, 36(3), 184-196.

Gilmore, L., Cuskelly, M., Jobling, A., \& Hayes, A. (2009). Maternal support for autonomy: Relationships with persistence for children with Down syndrome and typically developing children. Research in developmental disabilities, 30(5), 1023-1033.

Glenn, S., Dayus, B., Cunningham, C., \& Horgan, M. (2001). Mastery motivation in children with Down syndrome. Down Syndrome Research and Practice, 7(2), 52-59. 
Harris, S., Kasari, C., \& Sigman, M. D. (1996). Joint attention and language gains in children with Down syndrome. American journal of mental retardation: AJMR, 100(6), 608619.

Hoff-Ginsberg, E. (1987). Topic relations in mother-child conversation. First Language, $7(20), 145-158$.

Krakow, J. B., \& Kopp, C. B. (1983). The effects of developmental delay on sustained attention in young children. Child Development, 1143-1155.

Landry, S. H., Smith, K. E., Miller-Loncar, C. L., \& Swank, P. R. (1997). Predicting cognitive-language and social growth curves from early maternal behaviors in children at varying degrees of biological risk. Developmental psychology, 33(6), 1040.

Landry, S. H., Smith, K. E., Swank, P. R., Assel, M. A., \& Vellet, S. (2001). Does early responsive parenting have a special importance for children's development or is consistency across early childhood necessary?. Developmental psychology, 37(3), 387.

Laing, E., Butterworth, G., Ansari, D., Gsödl, M., Longhi, E., Panagiotaki, G., Paterson, S. \& Karmiloff- Smith, A. (2002). Atypical development of language and social communication in toddlers with Williams syndrome. Developmental Science, 5(2), 233-246.

Leigh, P., Nievar, M. A., \& Nathans, L. (2011). Maternal sensitivity and language in early childhood: A test of the transactional model. Perceptual and motor skills, 113(1), 281-299. 
Mason-Apps, E., Mason-Apps, E., Stojanovik, V., Houston-Price, C., \& Buckley, S. (in press). Longitudinal predictors of early language in infants with Down syndrome: a preliminary study. Research in Developmental Disabilities.

McCathren, R. B., Yoder, P. J., \& Warren, S. F. (1995). The role of directives in early language intervention. Journal of early intervention, 19(2), 91-101.

Marfo, K. (1990). Maternal directiveness in interactions with mentally handicapped children: An analytical commentary. Journal of Child Psychology and Psychiatry, 31(4), 531549.

Martin, G. E., Klusek, J., Estigarribia, B., \& Roberts, J. E. (2009). Language characteristics of individuals with Down syndrome. Topics in Language Disorders, 29, 112-132.

Morales, M., Mundy, P., Delgado, C., Yale, M., Messinger, D., Neal, R., \& Scwartz, H. K. (2000). Responding to joint attention across the 6- through 24-month age period and early language acquisition. Journal of Applied Developmental Psychology, 21, 283298.

Mullen, E. M. (1995). Mullen scales of early learning (AGS ed.). San Antonio, TX: Pearson.

Mundy, P., Sigman, M., Kasari, C., \& Yirmiya, N. (1988). Nonverbal communication skills in Down syndrome children. Child development, 235-249.

Mundy, P., Kasari, C., Sigman, M., \& Ruskin, E. (1995). Nonverbal communication and early language acquisition in children with Down syndrome and in normally developmental children. Journal of Speech, Language, and Hearing Research, 38, $157-168$.

Mundy, P., Hogan, A., \& Doehring, P. (1996). A Preliminary Manual for the Abridged Early Social Communication Scale (ESCS). Unpublished manuscript. 
Mundy, P., \& Gomes, A. (1998). Individual differences in joint attention skill development in the second year. Infant Behaviour and Development, 21, 469-482.

Mundy, P., Fox, N., \& Card, J. (2003). EEG coherence, joint attention and language development in the second year. Developmental Science, 6(1), 48-54.

Murray, L. \& Karpf, J. (2000). Coding scheme for structured mother-infant play interaction at 12 months, University of Reading.

Næss, K. A. B., Lyster, S. A. H., Hulme, C., \& Melby-Lervåg, M. (2011). Language and verbal short-term memory skills in children with Down syndrome: A meta-analytic review. Research in Developmental Disabilities, 32, 2225-2234.

Nozadi, S. S., Spinrad, T. L., Eisenberg, N., Bolnick, R., Eggum-Wilkens, N. D., Smith, C. L., Gaertner, A. K. \& Sallquist, J. (2013). Prediction of toddlers' expressive language from maternal sensitivity and toddlers' anger expressions: A developmental perspective. Infant Behavior and Development, 36(4), 650-661.

Pino, O. (2000). The effect of context on mother's interaction style with Down's syndrome and typically developing children. Research in Developmental Disabilities, 21(5), 329-346.

Scaife, M., \& Bruner, J. S. (1975). The capacity for joint visual attention in the infant. Nature, 253, 265-266.

Sigman, M., \& Ruskin, E. (1999). Continuity and change in social competence of children with autism, Down syndrome and developmental delays. Monographs of the Society for Research in Child Development, 64, 115-130.

Skuse, D., Wolke, D., \& Reilly, S. (1992). Failure to thrive: clinical and developmental aspects. Developmental psychopathology, 46-71. 
Snow, C. S. (1977). The development of conversation between mothers and babies. Journal of Child Language, 4, 1-22.

Steelman, L. M., Assel, M. A., Swank, P. R., Smith, K. E., \& Landry, S. H. (2002). Early maternal warm responsiveness as a predictor of child social skills: Direct and indirect paths of influence over time. Journal of Applied Developmental Psychology, 23(2), 135-156.

Stein, A., Woolley, H., Cooper, S. D., \& Fairburn, C. G. (1994). An observational study of mothers with eating disorders and their infants. Journal of Child Psychology and Psychiatry, 35(4), 733-748.

Sterling, A., \& Warren, S. F. (2014). Maternal responsivity in mothers of young children with Down syndrome. Developmental neurorehabilitation, 17(5), 306-317.

Sigman, M., \& Ruskin, E. (1999). Continuity and change in the social competence of children with autism, Down syndrome, and developmental delays. Monographs of the Society for Research in Child Development, 64.

Stoel-Gammon, C. (2001). Down syndrome phonology: Developmental patterns and intervention strategies. Down Syndrome Research and Practice, 7, 93-100.

Sullivan, M., Finelli, J., Marvin, A., Garrett-Mayer, E., Bauman, M.,\& Landa, R. (2007). Response to joint attention in toddlers at risk for autism spectrum disorder: A Prospective study. Journal of Autism and Developmental Disorders, 37, 37-48.

Tamis- LeMonda, C. S., Bornstein, M. H., \& Baumwell, L. (2001). Maternal responsiveness and children's achievement of language milestones. Child development, 72(3), 748767. 
Tomasello, M. (1995). Joint attention as social cognition. Joint attention: Its origins and role in development, 103-130.

Venuti, P., De Falco, S., Esposito, G., \& Bornstein, M. H. (2009). Mother-child play: children with Down syndrome and typical development. American journal on intellectual and developmental disabilities, 114(4), 274-288.

Venuti, P., de Falco, S., Esposito, G., Zaninelli, M., \& Bornstein, M. H. (2012). Maternal functional speech to children: A comparison of autism spectrum disorder, Down syndrome, and typical development. Research in developmental disabilities, 33(2), 506-517.

Wetherby, A. M., Woods, J., Allen, L., Cleary, J., Dickinson, H., \& Lord, C. (2004). Early indicators of autism spectrum disorders in the second year of life. Journal of autism and developmental disorders, 34(5), 473-493.

Wolke, D., Skuse, D., \& Mathisen, B. (1990). Behavioral style in failure-to-thrive infants: a preliminary communication. Journal of Pediatric Psychology, 15(2), 237-254.

Wright, C. A., Kaiser, A. P., Reikowsky, D. I., \& Roberts, M. Y. (2013). Effects of a naturalistic sign intervention on expressive language of toddlers with Down syndrome. Journal of Speech, Language, and Hearing Research, 56(3), 994-1008.

Yoder, P. J., \& Warren, S. F. (1998). Maternal responsivity predicts the prelinguistic communication intervention that facilitates generalized intentional communication. Journal of Speech, Language, and Hearing Research, 41(5), 12071219.

Zampini, L., Salvi, A., \& D'odorico, L. (2015). Joint attention behaviours and vocabulary development in children with Down syndrome. Journal of intellectual disability research, 59(10), 891-901. 
Zimmerman, I. L., Steiner, V. G., \& Pond, R. E. (2002). Preschool language scales (4th ed.).

San Antonio, TX: The Psychological Corporation

Appendix: Parent child interaction coding scheme

Coding Scheme for Structured Mother-Infant Play Interaction at 12 Months.

Play Manual for play sessions carried out according to instructions set out in Stein, Woolley, Cooper \& Fairburn (1994). Where indicated, the play manual has been modified and adapted from Stein, Woolley, Cooper \& Fairburn (1994)1, Wolke, Skuse \& Mathiasen (1990)2, Skuse, Wolke \& Reilly (1992)3, and Hinde \& Tamplin (1983)4. New items have been included and others excluded.

Structured Play Interaction Scales - Overview:

(Event Count (EC) and Rating Scale (RS))

Infant Measures: Vocalisations \% (RS/EC) 2\&3

Inhibition (RS) Emotional Tone (RS) 2\&3

Self-Regulation (RS)

Mother Measures: Verbal Control (EC) 4 Positive Expressed Emotion (EC) 1 Negative Expressed Emotion (EC) 1 Maternal Coercions/Intrusions (EC) 1 Maternal Verbal Elaboration (RS) Maternal Emotional Tone (RS) 2\&3 Sensitivity (RS) 2\&3

Joint Measures: General Atmosphere (RS) 2\&3 Reciprocity (RS) 2\&3

Lynne Murray and Janne C. Karpf (2000)

The Winnicott Research Unit

Department of Psychology

University of Reading

3 Earley Gate

Reading, RG6 6AL 
Infant Vocalisations:

Refers to non-crying utterances or to recognisable utterances embedded in crying. These may be cooing, babbling, consonant sounds or words. Crying, per se, no matter how varied, does not qualify. NOTE: for this item, also record how many (and which) actual words/word approximations the infant elicits.

1. Definitely quiet, no, or hardly any vocalisations. Guide: $0-2$ vocalisations.

2. Few vocalisations of short duration. Guide: 3-4 vocalisations.

3. Vocalisations occur as part of activities, but too intermittent to constitute vocal excitement, chatter or the like. Guide: 5-7 vocalisations.

4. Vocalisations constitute an obvious part of the infant's activity, infant vocalises for the sake of vocalising. Guide: 8-9 vocalisations.

5. Infant vocalises for most of interaction. Guide: at least 10 vocalisations.

Infant Inhibition:

Refers to how inhibited the infant seems in play and how participatory and comfortable in the situation. The very inhibited infant will show recurrent signs of wariness of toy, camera, Experimenter (whilst playing with the mother), and seek proximity with mother, as well as minimal motor movement / intensity when playing with toy as well as not explore toy or environment much. Thus this child may seem placid. The very comfortable infant will not show signs of inhibition whilst playing with the mother, and feels comfortable enough with the Experimenter not to have relapses of shyness/ coyness/ proximity seeking between toys.

1. Very Inhibited. Hardly any variation in intensity when playing with toy. Recurrent signs of wariness of toys, their function, the camera, Experimenter or other environmental circumstances. Repeated proximity seeking with mother or hardly any exploring. Overall impression is either very shy or inhibited most of the time, perhaps to the extent that warming up to the toy may not happen at all or only towards the end of the $2 \frac{1}{2} 2$ minutes.

2. Inhibited. Seems reluctant to initiate engagement over toy or may be preoccupied with other more familiar environmental issues (in the room or outside) and thus seems easily affected or distracted by outside factors (not as a result of poor attention, but perhaps more because this is what is familiar to the child and it is a way to shut out other unfamiliar objects/situations). It may well take time for the child to warm up to the toy on each occasion, but he or she will play with the toy, albeit usually in a quiet placid way. Variations in the intensity with which the infant plays with the toy may not be very discriminable. This child will repeatedly check the camera or Experimenter, often with a concerned look or frown, 
3. Moderately Relaxed. This infant seems sociable or otherwise engaged with the environment about half the time. Thus, will show sociable/engaged behaviour on and off with moderate or more than just very brief instances of shyness, inhibition or wariness. There is detectable variation in the intensity of play with toy.

4. Relaxed. This infant does not seem affected by the situation most of the time, and seems sociable or engaged with the toy, mother, environment or even Experimenter most of the time. There may be instances of brief coyness, wariness or reassurance seeking behaviour. There is a detectable variation in the intensity in the manner he or she engages with things.

5. Very Relaxed. This child does not seem affected by the situation at all and seems content playing with the toy or engaging with mother, environment or even Experimenter. This is not to say the infant will be loud and bold, but rather that he or she gets on with the playing or has the ability to explore other aspects in the room without appearing inhibited in his/her actions, and without this appearing to be a distraction mechanism (so the child is likely to share this experience with others in the room). The infant, who does not physically move around a lot, can still be engaging with the environment in a relaxed or natural way. Detectable variation in intensity in the manner he or she engages with things.

Infant Emotional Tone:

Refers to how happy or unhappy and fussy the infant is during the session. Take into account positive or negative verbal as well as non-verbal signs of happiness or frustration. Those infants who become very absorbed but occasionally 'let out' a positive signal will tend towards being more happy than not happy.

1. Very Unhappy. Infant seems very unhappy during the whole session, gets upset, cries and fusses for most of the session, strong protest, may wail.

2. Unhappy. At times rather unhappy and whining, fussy, short verbal protest, but responds happily to encouragement. There may be some non-verbal evidence of frustration (such as frowning).

3. Moderately Happy. Content (smiles and vocalises positively) half the time, may become briefly upset, equal mix of positive and negative affect (verbal and non-verbal. (An infant who appears neutral in tone receives a code of $3 \mathrm{~N}$ ).

4. Happy. Appears to be in a happy state more than half the time; smiles and happy vocalisations dominate, may have one brief period of negative affect or short periods of neutral mood.

5. Very Happy. Radiates happiness, highly excited, nothing is upsetting (never becomes upset), animated expressive, smiling, gleeful. 
Infant Self-Regulation:

Refers to how well regulated (emotionally and physically) the infant appears generally and in response to positive, negative or neutral events during the play (including toy changes, and in particular during the last three toy sessions which are supposed to be more difficult and likely to elicit more frustration). Note the number of state-changes the infant may cycle through, as well as whether strategies adopted are of a self-soothing (e.g. sucking or fiddling) or selfdistracting (e.g. focusing on alternative objects or reorienting in relation to mother/toy) nature. Thus, this is the overall impression of how emotionally and physically well regulated the infant expresses him or herself, or how 'contained' they seem in the situation. It is the responses emanating from the child that are of importance. A well-regulated infant will show a range of well-modulated responses to likes and dislikes, whereas a dysregulated infant will resort to a limited and often extreme (e.g. marked hyper- or over activity or 'stillness' / emotional 'flatness') type of response. Incomplete or sudden bursts of movement or action and stereotypies all contribute to disorganisation when they do not make sense in the context of the infant's activity. Strange vocalisations (screeching quality, odd crying or breathing) and fearful facial expressions (which may be momentary) are also indicators of disorganisation. Play quality is likely to be affected with dysregulation. Thus, a child who is dysregulated may not engage in constructive, enjoyable play (e.g. may instead be throwing toy around randomly or just handling it without exploring).

1. Very dysregulated. Physically in terms of being hyper-, over- or under-active a most of the time. Emotionally in terms of throwing tantrums with squirming and crying and/or screaming for longer periods, or marked change between tantrums and over-excitement. Alternatively, this infant may appear emotionally very flat or apathetic. The play session may sometimes have to be cut short. Also, disorganised behaviours, such as stilling or stereotypies may occur.

2. Dysregulated. Hyper-, over- or under-active a lot of the time but may have moments of less (or more) active or normal activity level. Brief instances of fussing, crying or screaming which may be recurrent. There may be an instance of disorganised behaviour.

3. Moderately Regulated. Normal activity level more than half the time, and responds appropriately on an emotional level about half the time or more. No instances of crying or screaming although fussing or squirming may be seen. No disorganised behaviour.

4. Well Regulated. Normal activity level most of the time and mostly responds appropriately on an emotional level. Seems 'contained' most of the time, but may have brief moments of fussing. No disorganised behaviour, and quality of play is good.

5. Very Well Regulated. Normal activity level most of the time, and responds appropriately on an emotional level throughout the session. Although there may be very transient moments of fussing, the infant very quickly resumes play, and seems very 'contained' in the situation. No disorganised behaviour apparent. 


\section{Maternal Verbal Control Behaviour:}

Rate Strong and Mild Control, utterances counted as separate if 3 seconds apart. Take tone of voice into account. If two statements are the same (and they follow each other), they are counted as only one statement. Take care not to code the maternal style, for example, the quietly spoken mother is not necessarily less verbally controlling than the loudly spoken mother is.

Strong Control (commands, which are often imperatives)

Commands ('Come here!', 'Bring the...!')

Strong Request ('Look here!)

Inhibition ('That won't work')

Forbids ('No, don't do...!')

Cautioning ('I will take it away...')

Correcting (No, you have to do...'

Mild Control (some attempt to influence)

Suggests ('How about doing...')

Prompts ('The circle goes in here...', 'Where does this go?', 'Who is it?')

Gentle Requests ('Would you like to...', 'Do you want...', 'Can you give...')

Joint Suggestions ('Shall we do...', 'How about if we...')

Guides (Information accompanied by practical help)

The total number of utterances of Strong and Mild Verbal Control from the mother is added up, to give a score from zero to the actual count (i.e. $0 \rightarrow$ actual count of event).

In addition, the total number of utterances by the mother is recorded.

Maternal Positive Expressed Emotion:

Any positive, affectionate or complimentary comment directed at the infant. Include here statements that are fundamentally neutral but said in positive tone of voice (e.g. 'That's cheating', in an affectionate manner). Include also clapping with vocalisation if directed at infant, not necessarily with name but in response to infant's action. 


\section{Maternal Negative Expressed Emotion:}

Any critical, negative or denigratory expressions directed at the infant. Include here statements that are fundamentally neutral but said in negative tone of voice (e.g. 'That's cheating!', while laughing with an edge to it). Note: ordinary limit setting without denigratory tone does not count as Negative Expressed Emotion (e.g. 'Don't do that' could be limit setting / safety issues). Thus, negative expressed emotion are primarily based on negative (angry, critical or rejecting) comments (i.e. the content rather than tone) directed at the infant.

\section{Maternal Coercions/Intrusions:}

This refers to the number of times the mother is coercive or intrusive in play. Coercions are manifested as a forceful positioning of the infant or as forceful guidance to make the infant achieve the play task. This is the case when physically making the child post the correct shape into the sorter or hammer the ball into the hole when there is no apparent volition in the infant to do so. Coercing an infant is very different from guiding or jointly showing how. Intrusive actions inappropriately cut across, take over or disrupt the infant's activity. Intrusive physical proximity or actions that constantly distract and cut across the infant's play are counted. Very forceful verbal instructions that have a cutting across effect and are inappropriately disruptive in impact are counted as intrusions but usually intrusions have a physical intervention component.

\section{Maternal Verbal Elaboration:}

This dimension codes the extent to which a mother elaborates verbally on the toy with which she is playing with the infant. This dimension does not attempt to rate the effectiveness or appropriateness of the style (this is picked up by sensitivity, coercion/intrusion, verbal control and interaction measures). When rating this dimension, take into account elaborative strategies (or the absence of them) when they are directed at the infant, but do not take into account aspects of the infant's behaviour:

$\square$ Elaborating and absence of elaboration

Elaborating is a measure of the verbal expansion of use of the toy or information about the toy, which adds to the infant's experience. Verbal elaboration includes comments on form or function (e.g. commenting on the shapes and colours of the balls or shapes (even if this seems beyond the infant's grasp)) or relating it to other more familiar toys/objects the infant may already possess or be familiar with or people the infant knows (e.g. 'daddy' while playing with the telephone, when this goes further than just 'naming' the picture, i.e. 'daddy's calling' or 'hello daddy'). The form of the comment can be instructional ('shall we build a castle' or 'the blue one goes in there') or explanatory ('that's where the ball comes out' or 'the telephone is ringing'). Do not count general comments about infant likes and dislikes. A mother may also comment or elaborate on vocalisation made by the infant.

At the lower end of the scale of maternal verbal elaboration are mothers who never or hardly ever demonstrate verbal elaboration during the play. When they do, elaborations are very 
simple, only very occasional, and include only naming of toy, colour, shape or picture (on phone) or they might verbalise the noise the toy makes, e.g. 'bang, bang' or 'ring, ring'. At the higher end of the scale are mothers who demonstrate frequent, 'simpler' elaborations (again, mentioning of colour, noise) or other flexible/imaginative uses of the toy (e.g. 'shape sorter as a drum' or 'bricks in tower', or attempt to engage the infant in familiar games using the toy such as 'peek-a-booh') or, usually less frequent, higher quality, or 'educational' elaborations (e.g. by counting aloud number of items or comparing toy or function to another familiar object or concept, for example 'red, green, like your traffic light!' or 'daddy is calling from work'). Do not necessarily count stating the number of items (e.g. 'two balls') as an instance of 'higher quality counting' (e.g. 'one, two, three.....').

1. No verbal elaboration. This mother never elaborates verbally on form, shape, function, colour or count and never likens the infant's experience to something familiar.

2. Little verbal elaboration. This mother elaborates verbally a few times (guide: 1-5 times), but never uses more sophisticated ways of relating the toy to more familiar aspects of the infant's world. The types of elaborations include simple naming of toy, colour, shape or noise. [If there are signs of a flexible style of elaboration, but the total number of elaborations is small, forcing a rating of 2 is possible].

3. Moderate verbal elaboration. This mother's elaborations are frequent (guide: $5+$ times) but not sophisticated. Although she may show some flexibility in referring to the toy (e.g. by likening the shape sorter to a drum), she never counts or extends the concept to other familiar concepts. Her elaborations are kept simple. [If there are signs of a higher quality style of elaboration, but the total number of elaborations is very small, or the mother uses this higher quality style once or twice while not making use of any simpler elaborations, forcing a rating of 3 is possible].

4. Good verbal elaboration. To get this score, the mother must make use of at least one higher quality and at least a few other 'simpler' elaborations. [Alternatively, she could be using higher quality elaborations on a number of occasions, while making no, or little use of simpler elaborations].

5. Very good verbal elaboration. This mother frequently makes use of both high quality and 'simpler' elaborations. To get this score, she must have at least two high quality and a 'fair few' simpler elaborations. [Alternatively, she could be using higher quality elaborations extensively, while making no, or little use of simpler elaborations].

Maternal Emotional Tone:

Refers to how happy or unhappy and fussy the mother is during the play. Some mother's may laugh for no apparent reason, this is not necessarily a sign of happiness, but could indicate that the mother is nervous or uncomfortable - if it is obviously nervous don't count it as happy. Equally, a mother who seems quiet may not be unhappy, but if she seems distant or unfocused or drifts off for periods she is probably not very happy.

1. Very Unhappy. This mother seems very unhappy or distant during the whole play session or for long periods during it. She is either upset and fusses for most of the session or very distant for longer periods. Her verbal protest may be strong. 
2. Unhappy. This mother seems rather unhappy and fussy (short verbal protest) or distant more than half the time.

3. Moderately Happy. This mother seems content (smiles and vocalises positively) half the time, may become very briefly upset or distant, mainly neutral mood. (If constantly neutral, code of $3 \mathrm{~N}$ is given)

4. Happy. This mother appears to be in a predominantly happy state more than half the time, smiles and vocalises positively, some periods of neutral mood occur.

5. Very Happy. This mother seems very happy throughout the session (never becomes upset), is animated, expressive and smiley.

Maternal Sensitivity:

Refers to how sensitively the mother is attuned and responds to the infant's signals. When rating sensitivity during play, attention should be paid to the positioning of the mother and infant (distance between the mother and infant, eye to eye contact possible, freedom of movement possible, a highly sensitive mother may reposition herself rather than her infant when repositioning is necessary). Note: it must be remembered, that the mother has also been instructed to try to keep the infant from facing away from the camera). Attention should also be paid to the method used to attain or regain interest in a toy, as well as to the picking up cues from the infant (such as 'asking' for help or wanting to be left to explore alone) and responding to them in a temporally contingent manner. Furthermore, comments and feedback on infant behaviour and accomplishments as well as variation in stimulation during play all contribute to this dimension.

1. Highly Insensitive. The extremely insensitive mother seems geared almost exclusively to her own wishes, moods and activity. I.e. mother's interventions and initiations of interaction are prompted or shaped largely by signals within herself; if they mesh with the infant's signals, this is often no more than coincidence. This is not to say that the mother never responds to the infant's signals, as sometimes she does if these signals are intense enough, prolonged enough or often repeated enough. The delay in response is in itself insensitive. Furthermore, since there is usually a disparity between the mother's own wishes and activity and infant's signals, the mother, who is largely geared to her own signals, routinely ignores or distorts the meaning of he infant's behaviour. Thus, when the mother responds to her infant's signals, her response is characteristically inappropriate in kind, or fragmented and incomplete.

2. Insensitive. The mother frequently fails to respond to infant's communications appropriately and/or promptly, although she may on some occasions show capacity for sensitivity in her responses to and interactions with her infant. Her insensitivity seems linked to an inability to see things from the infant's point of view. She may be too frequently preoccupied with other things and therefore inaccessible to the infant's signals and communications. She may also misperceive signals and interpret them inaccurately because of her own wishes or defences. Furthermore, she may know well enough what the infant is communicating but be disinclined to give him/her what he/she wants - because it is inconvenient or she is not in the mood for it, or because she is determined not to 'spoil' 
$\mathrm{him} / \mathrm{her}$. She may delay an otherwise appropriate response to such an extent that it is no longer contingent to her infant's signal, and indeed perhaps is no longer appropriate to his state, mood or activity. This mother may also respond with seeming appropriateness to infant's communications but break off the transactions before the infant is satisfied, so that their interactions seem fragmented and incomplete or her responses perfunctory, half-hearted or impatient. Despite such clear evidence of insensitivity, however, this mother is not as consistently or pervasively insensitive as the mother with even lower ratings. This mother can modify her own behaviour and goals and can show some sensitivity in her handling of the infant, either when the infant's wishes, moods and activity are not too deviant from the mother's wishes and moods, or when the infant is truly distressed or otherwise communicating very forcefully and compellingly.

3. Inconsistently Sensitive. Although this mother can be quite sensitive on occasion, there are some periods in which she is insensitive to her infant's communication. The mother's inconsistent sensitivity may occur for any one of several reasons, but the outcome is that she seems to have lacunae in regard to her sensitive dealings with the infant - being sensitive at some times or in respect to some aspects of the infant's experience, but not in others. Her awareness of the infant may be intermittent and often fairly keen, but sometimes imperious. Her perception of the infant's behaviour may also be distorted in regard to one or two aspects although it is accurate in others. She may be prompt and appropriate in response to the infant's communications at some times and in most respects, but either inappropriate or slow at times in other respects. On the whole, however, she is more frequently sensitive than insensitive. What is striking is that a mother, who can be as sensitive as she is on so many occasions, can be so insensitive on other occasions.

4. Sensitive. This mother also interprets infant's communications accurately and responds to them promptly and appropriately - but with less sensitivity than mothers with higher ratings. She may be less attuned to infant's more subtle behaviours compared with the highly sensitive mother. Or, perhaps because she is less skilful in dividing her attention between infant and competing demands, she may sometimes 'miss her cue'. The infant's clear and definite signals are, however, neither missed nor misinterpreted. This mother empathises with the infant and sees things from the infant's point of view. Her perceptions of the infant's behaviour are not distorted. Perhaps because her perception is less sensitive than that of other mothers with a higher rating, her responses are not as consistently prompt or as finely appropriate. Although there may be occasional little 'mismatches', the mother's interventions are never seriously out of tune with infant's tempo, state and communications.

5. Highly Sensitive. This mother is exquisitely attuned to infant's signals and responds to them promptly and appropriately. She is able to see things from the infant's point of view; her perceptions of signals and communications are not distorted by her own needs and defences. She 'reads' the child's signals and communications skilfully, and knows what the meaning is of even subtle, minimal and understated cues. She nearly always gives the infant what he/she indicates he/she wants, although not invariably so. When she feels that it is best not to comply with the demand - if, for example, the infant is too excited, over-imperious, or wants something he/she should not have - she is tactful in acknowledging his communication and in offering an acceptable alternative. She has 'well-rounded' interactions with the infant, so that the transaction is smoothly completed and both she and the infant feel satisfied. 
Finally, she makes her responses temporally contingent upon the infant's signals and communications.

General Atmosphere of the Interaction:

This refers to the extent of how harmonious or disharmonious (discordant and conflictual) the overall interaction between the mother and infant is. Consider the infant's expression in particular (to be discordant, the infant may either adopt a strategy of resisting, ignoring or avoiding).

1. Very much discord and conflict.

2. Generally negative and/or conflictual; may be occasionally positive.

3. Neutral or bland; overall the atmosphere seems neither positive nor negative.

4. Generally positive and friendly, hardly any instant of conflict or negative feelings may be expressed.

5. Very harmonious, agreeable and peaceful, no conflict or negative feelings expressed.

Reciprocity:

This refers to the extent of mutual interchange between mother and infant. The infant's input is received and responded to by the mother and vice versa. In particular, the degree of joint orientation and co-ordination of the actions between the mother and the infant in achieving a task goal is rated. The shared co-ordination and turn taking makes a very important contribution to this dimension. Referencing would be expected in higher reciprocal interaction, although the dyad may be so absorbed in sharing actions that there is no need for sharing the gaze as well.

1. No Reciprocity. Hardly any reciprocity is observed; there is no turn taking or communication, the mother and infant engage in different things at a given time and shared co-ordination is hardly ever observed.

2. Little Reciprocity. Reciprocal interaction rarely occurs, and only occasionally do the mother and infant incorporate the other's suggestions. Turn taking is very rare. It is rare that the mother and infant are manipulating the same aspects of a task or that they are actually coordinating their efforts around the toy in focus and the interaction around the toy is tuned in.

3. Moderate Reciprocity. The session is half the time characterised by reciprocal interaction.

4. Much Reciprocity. Much of the session is characterised by reciprocal interaction, most of the exchanges are mutual and characterised by turn taking, and there is joint engagement.

5. Very Much Reciprocity. The entire session is characterised by reciprocal interaction, exchanges are mutual, finely tuned, co-ordinated and smooth. 